\title{
Biomonitoring in environmental medicine - results of LARS
}

\author{
U. Rolle-Kampczyk ${ }^{1}$, U. Diez ${ }^{2}$, M. Rehwagen ${ }^{1}$, M. Richter ${ }^{1}$, \\ M. Borte ${ }^{2} \&$ O. Herbarth ${ }^{1}$ \\ ${ }^{1}$ Centre for Environmental Research Leipzig-Halle, \\ Department of Human Exposure Research and Epidemiology, Germany \\ ${ }^{2}$ Hospital Sankt Georg Leipzig, \\ Children`s Hospital and Outpatient Ambulance, Germany
}

\begin{abstract}
The Leipziger allergy risk study (LARS) investigated, during a period of five years, the influence of a typical indoor contaminant burden on the development of allergies and upper respiratory tract infections in children with an allergy-risk. During the third year of life, biomonitoring with the focus on passive smoking was carried out. Therefore, typical tobacco smoke related indoor volatile organic compounds (VOC) as well as excretion of certain VOC metabolites in urine were measured. The data analyses are based on parent-completed questionnaires, exposure measurements and medical examination. Generally, residences with a high burden of passive smoking showed higher benzene concentrations than nonsmoking ones. Significant differences between the excretion of VOC metabolites could be found between passive smoking and unburdened children. Obstructive bronchitis was observed more frequently in the children being exposed to increased concentrations of benzene as well as toluene, $\mathrm{m}, \mathrm{p}$-xylene and styrene. In addition, occurrence of atopic symptoms like eczema was found to be associated with the excretion of the VOC metabolite of toluene Sbenzyl-mercapturic acid (SBMA). Therefore, evaluation of external exposure should be supplemented with the evaluation of internal exposure.
\end{abstract}

Keywords: biomonitoring, passive smoking, allergy risk children, VOC, metabolites. 


\section{Introduction}

Little is known about the influence of the environment on the occurrence of allergies in the first years of life, but allergic diseases are increasing all over the world $[1,2]$.

The LARS study is a prospective cohort study investigating the influence of chemical indoor exposure on the occurrence of atopic symptoms and upper respiratory tract infections in children during their first years of life.

Chemical indoor exposure is defined as the burden of volatile organic compounds (VOC) in the children's residences.

Indoor VOC concentrations are influenced by certain factors such as renovation, furniture and passive smoking. Evidence is mounting that VOCs have different effects on human health such as development of atopic diseases [3-5]. This study wanted to clarify the role of passive smoking on the development of atopic diseases by assessment of the internal dose of tobacco smoke related VOC eliminated in urine. The influence of passive smoking on the children's health has been described by various authors [6-12].

Tobacco-smoke related VOCs in indoor air were analysed by different research groups. The International Agency for Research on Cancer (IARC) defined benzene as one component related to smoke exposure [13]. Other authors reported toluene, xylenes, styrene and ethylbenzene as relevant as well [3, 14, 15]. The biomonitoring had the aim to objectify the external exposure and to look for exposure associated health effects. Because, only a contaminant in the body can cause effects. Therefore, the internal exposure was analyzed by measuring metabolites of the contaminants in urine [14-17]. The measurement of specific metabolites is important, because so it is possible to avoid an overload by endogenous metabolic processes. S-phenylmercapturic acid (SPMA) and S-benzylmecapturic acid (SBMA) were measured as specific metabolites for the exposure to benzene and toluene [18-28]. Measurement of cotinine, a biomarker for nicotine, was used to objectify the questionnaire data of concerning the burden of the children's passive smoking.

\section{Material and methods}

\subsection{Study population}

For the original "LARS-Study" (Leipzig's Allergy Risk Study) 475 premature infants and newborns with parental risk for allergic disease were recruited from a total of 3540 live births in the city of Leipzig, born between March 1995 and March 1996.

The allergic risk factors were defined as (a) cord blood $\operatorname{IgE}>0.9 \mathrm{kU} / 1$, (b) children with double-positive allergy history, [c] children with a birth weight of $1500-2500 \mathrm{~g}$. Infants of the same study population with these risk factors but without indoor burden (assessed by indoor measurements and questionnaire responses) served as control subjects. This is case-control study within the prospective cohort study. 
At the end of the infants' third year of life, the study plans called for a clinical examination, indoor VOC measurements, biomonitoring and completion of a detailed questionnaire on the children's illnesses and disease symptoms (e.g., wheezing, obstructive bronchitis and eczema), parental lifestyle factors (e.g., smoking, renovation of residence, area of residence, pets etc.). Only 192 3-yearolds were entered into biomonitoring as they fulfilled all 4 conditions of participation: written informed parental consent, a completed questionnaire especially concerning the part on smoking, a consent to perform indoor measurements and a urine sample. Parents who did not give their consent were not followed further.

\subsection{VOC measurement}

Samples for the analyses of the indoor VOC burden were collected in the children's bedrooms using OVM 3500 passive collectors (3M, Neuss, Germany) for a period of four weeks.

VOCs were quantitatively analysed by capillary gas chromatography with FID and ECD. A gas chromatograph type Autosystem by Perkin Elmer was used (capillary columns PVMS $/ 5, \mathrm{SB} 11$ and DMS; $50 \mathrm{~m}, \mathrm{ID}=0.32$, slice thickness 1 $\mu \mathrm{m}$; carrier gas nitrogen, $14.5 \mathrm{psi}$, injection volume $2 \mu \mathrm{l}$, split 1:10; temperature program: $40^{\circ} \mathrm{C}, 2^{\circ} \mathrm{C} /$ min-- $150^{\circ} \mathrm{C}$ ). To check the correctness, all analyses were measured with two different polar columns and using the method of the internal standard (internal standard $=$ cyclododecan $)$.

\subsection{Urine analysis}

The mercapturic acids were analyzed after chromatographical separation with a RP 18 column $(15 \mathrm{~cm})$ and ionisation with the Turbo-Ionspray-source (TIS) on LC/MS/MS device API 300 by PE SCIEX, using tandem-mass spectrometry in negative mode.

Cotinine was analyzed after extraction with dichloromethan from urine and chromatographic short separation with a RP 18 column $(5 \mathrm{~cm})$ using chemical ionization under atmospheric pressure (APCI) also on LC/MS/MS device in positive mode.

Analysis of creatinine as a measure for individual urinary dilution was used for standardization of the metabolite concentrations, therefore, referring to $1 \mathrm{~g}$ of creatinine. For the measurements, the HPLC Gold by Beckmann (with Diodenarray-detector, column: RP18, $4.6 \mathrm{~mm}$ ID, $5 \mu \mathrm{m}, 15 \mathrm{~cm}$ column of Knauer) was used.

\subsection{Statistical analysis}

Statistical analyses were performed applying the work package STATISTICA for Windows (version 5.1, 1997 edition, Statsoft Inc., Tulsa OK, USA). The Kolmogorov-Smirnov test revealed non-normal distribution of data. The MannWhitney U-test was used to analyze differences between data concerning VOC burden and excretion of metabolites and questionnaire data concerning passive 
smoking and health complaints. In addition, odds ratios (OR) based on the maximum likelihood method with a 95\% confidence interval (CI) were calculated. As a reference data set was not available, evaluation was carried out by comparing the results with percentile data based on our own measurements. Concentrations exceeding the $75 \%, 80 \%, 90 \%$ or $95 \%$ percentile were defined as threshold values for certain compounds.

\section{Results}

Only 192 3-year-olds were entered into biomonitoring as they fulfilled all conditions of participation. $27 \%$ of the parents confirmed to smoke in the home. Trend analysis revealed a higher benzene concentration in residences where either or both parents smoked as presented in figure 1 .

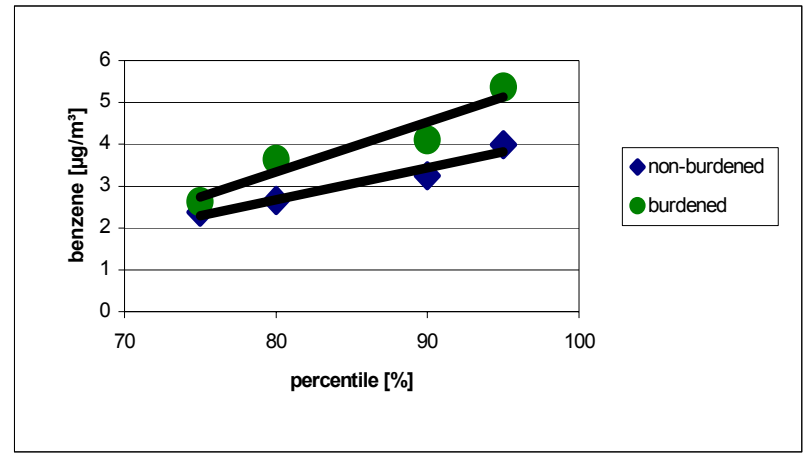

Figure 1: Concentrations of benzene in indoor air of children with and without burden of passive smoking. Measured concentrations in both groups are presented on the y-axis and assigned to the $75 \%$, $80 \%, 90 \%$ and $95 \%$ percentile presented on the $\mathrm{x}$-axis.

In contrast, significant differences could be found for the excretion of the specific metabolites SPMA, SBMA and cotinine as shown in table 1.

Table 1: Association between burden of passive smoking and excretion of metabolites.

\begin{tabular}{|l|l|l|l|}
\hline Metabolite & $\mathrm{p}$ & $\begin{array}{l}\text { non-burdened children } \\
\text { mean value } \\
{[\mu \mathrm{g} / \mathrm{g} \text { creatinine }]}\end{array}$ & $\begin{array}{l}\text { burdened children } \\
\text { mean value } \\
{[\mu \mathrm{g} / \mathrm{g} \text { creatinine }]}\end{array}$ \\
\hline SPMA & 0.044 & 2.44 & 3.32 \\
\hline SBMA & 0.043 & 37.97 & 44.4 \\
\hline Cotinine & 0.002 & 4.43 & 9.08 \\
\hline
\end{tabular}

Than was tested which health effects are associated with passive smoking related VOC. The Mann-Whitney-U-test showed significant associations to the occurrence of eczema and obstructive bronchitis like demonstrated in table 2 . 
Toluene concentration exceeding the $75 \%$ percentile of the in indoor air $(>19.83$ $\mu \mathrm{g} / \mathrm{m}^{3}$ ) was significantly associated with the occurrence of eczema during the third year of life in burdened children $(\mathrm{OR}=13$, CI: 1.63-103.12, $\mathrm{p}=0.008)$.

Table 2: Associations between single VOCs and occurrence of symptoms in participants under burden of passive smoking.

\begin{tabular}{|c|c|c|c|c|}
\hline Symptom & VOC & $\mathrm{p}$ & $\begin{array}{c}\text { mean value } \\
{\left[\mu \mathrm{g} / \mathrm{m}^{3}\right]} \\
\text { non-burdened } \\
\text { children }\end{array}$ & $\begin{array}{c}\text { Mean value } \\
{\left[\mu \mathrm{g} / \mathrm{m}^{3}\right]} \\
\text { burdened } \\
\text { children }\end{array}$ \\
\hline Eczema & Toluene & 0.03 & 15.12 & 29.34 \\
\hline Bronchitis & Toluene & 0.018 & 14.79 & 25.98 \\
& Benzene & 0.013 & 1.76 & 3.11 \\
\hline
\end{tabular}

Further association between certain VOC and bronchitis could be found for styrene concentrations above the $75 \%$ percentile $\left(>1.17 \mu \mathrm{g} / \mathrm{m}^{3}\right)$ revealed an OR of 6.4 (CI: 1.01-40.53, p=0.04), and m,p-xylene concentrations above the $80 \%$ percentile $\left(>11.1 \mu \mathrm{g} / \mathrm{m}^{3}\right)$ revealed an OR of $10(\mathrm{CI}: 1.045-161.7, \mathrm{p}=0.02)$.

Moreover, associations between excretion of metabolites and the occurrence of certain illnesses were observed. OR calculation showed that the occurrence of eczema in burdened children was significantly related to an increased excretion of the toluene metabolite SBMA in urine above the $80 \%$ percentile and are shown in table 3 .

Table 3: Association between burden with passive smoking and the occurrence of eczema.

\begin{tabular}{|c|c|c|}
\hline $\begin{array}{l}\text { SBMA } \\
\text { percentile }[\%] \text { and } \\
\text { (concentration }[\mu \mathrm{g} / \mathrm{g} \text { creatinine] })\end{array}$ & $\mathrm{p}$ & $\begin{array}{c}\text { Odds ratio (OR) } \\
\text { and }\end{array}$ \\
\hline$>80(>30.14)$ & 0.019 & $\begin{array}{c}9 \\
\text { confidence interval }(\mathrm{CI})\end{array}$ \\
\hline$>90(>69.58)$ & 0.03 & $\begin{array}{c}16 \\
1.07-239.1\end{array}$ \\
\hline$>95(>385.16)$ & & 16 \\
& 0.03 & $1.00-2.39$ \\
\hline
\end{tabular}

No significant relationship could be found between concentrations of single VOCs in the air of the children's rooms and excretion of the metabolites.

Thus, we looked for another relationship between indoor VOC burden and the elimination of metabolites. We could find that, despite the lack of metabolic relationship, measured benzene concentrations were associated with excretion of the nicotine metabolite cotinine (table 4). This emphasize the relationship of the 
indoor benzene burden to passive smoking. So, it was possible to reflect from a body burden to an exogenous exposure source.

Table 4: Association between single VOC burden and urinary cotinine excretion without considering passive smoking.

\begin{tabular}{|l|l|}
\hline & Cotinine 95\% \\
\hline Benzene $75 \%$ & $\mathrm{p}=0.013, \mathrm{OR}=11.6$, CI: $1.21-110.39$ \\
\hline Benzene $80 \%$ & $\mathrm{p}=0.003, \mathrm{OR}=17.27$, CI: $1.79-165.98$ \\
\hline Benzene $90 \%$ & $\mathrm{p}=0.004$, OR=18, CI: 2.6-124.45 \\
\hline Benzene $95 \%$ & $\mathrm{p}=0.0002$, OR=57, CI: $6.66-487.1$ \\
\hline Styrene $80 \%$ & $\mathrm{p}=0.004$, OR=7.27,CI: $1.11-47.28$ \\
\hline
\end{tabular}

Abbreviations: $\mathrm{OR}=$ Odds ratio, $\mathrm{CI}=$ Confidence interval, $\mathrm{n}=122$.

To improve the interpretation of the association between cotinine excretion and benzene, SPMA, the benzene metabolite was further metabolised. A significant relationship to passive smoking was found when SPMA excretion exceeded the $75 \%$ and $80 \%$ percentile and cotinine excretion exceeded the $75 \%$ and $80 \%$ percentile (table 5 ).

Table 5: Associations between burden of passive smoking with cotinine and SPMA.

\begin{tabular}{|c|c|c|c|}
\hline $\begin{array}{c}\text { Metabolite } \\
\text { in } \\
\text { urine }\end{array}$ & $\begin{array}{c}\text { Burden } \\
\text { with } \\
\text { passive smoking }\end{array}$ & $\begin{array}{c}\text { Metabolite } \\
\text { in } \\
\text { urine }\end{array}$ & $\begin{array}{c}\text { Burden } \\
\text { with } \\
\text { passive smoking }\end{array}$ \\
\hline $\begin{array}{c}\text { Cotinine } \\
>75 \% \text { percentile }\end{array}$ & $\mathrm{p}=0.0006$, & SPMA & $\mathrm{p}=0.03$, \\
$(10.17[\mu \mathrm{g} / \mathrm{g}]$ & $\mathrm{OI}=4.42$ & $>75 \%$ percentile & $\mathrm{OR}=2.46$ \\
creatinine $)$ & & $\begin{array}{c}4.44[\mu \mathrm{g} / \mathrm{g}] \\
\text { creatinine })\end{array}$ & $1.09-5.54$ \\
\hline $\begin{array}{c}\text { Cotinine } \\
>80 \% \text { percentile }\end{array}$ & $\mathrm{p}=0.0002$, & SPMA & $\mathrm{p}=0.025$, \\
$(13.99[\mu \mathrm{g} / \mathrm{g}]$ & $\mathrm{CI}: 2.16-13.36$ & $\begin{array}{c}80 \% \text { percentile } \\
(4.89[\mu \mathrm{g} / \mathrm{g}]\end{array}$ & $\mathrm{OR}=2.79$ \\
creatinine $)$ & & creatinine $)$ & $1.17-6.64$ \\
\hline
\end{tabular}

Abbreviations: $\mathrm{OR}=$ Odds-Ratio, $\mathrm{CI}=$ Confidence interval.

\section{Discussion}

The data analysis showed that apart from benzene no increased VOC concentrations could be found in the residences under burden of passive smoking.

A reasonable explanation could be that measurements were conducted in the children's bedrooms where active smoking is usually avoided. The measured 
significant higher concentrations of the metabolites SPMA, SBMA and cotinine in urine of passive smoke burdened children may due to exposure while staying in common rooms of the residence.

Assignment of single VOCs to certain symptoms and illnesses revealed a significant association between the toluene burden and the occurrence of eczema. Significant associations of obstructive bronchitis were found with benzene and toluene as well as for styrene and m,p-xylene when in higher concentrations, caused possibly by resulting from the irritating mucosal effects of these substances at those concentrations. These findings correspond to results of previous investigations revealing associations between passive smoking and the occurrence of certain symptoms in 1-year old children [6, 14].

Furthermore, the excretion of SBMA as a specific toluene metabolite was related to passive smoking and occurrence of eczema. The burden of passive smoking may contribute to atopic sensitization by increasing the $\operatorname{IgE}$ synthesis [10]. The MAS study revealed a relationship between pre- and postnatal burden of passive smoking and sensitization to food allergens [10, 11]. Already collected data will be further analyzed to help explain these aspects.

Additional, an association between the burden of passive smoking and the related exposure to benzene and toluene was indirectly analyzed by measuring urinary excretion of metabolites. Therefore, evaluation of external exposure should be supplemented with the evaluation of internal exposure to clarify possible associations with certain health effects.

Our findings indicate that children under risk of atopy do react sensitively to chemical substances such as passive smoking. They further show that these children have an increased risk to obstructive bronchitis and eczema.

\section{References}

[1] ISAAC: Worldwide variation in prevalence of symptoms of asthma, allergic rhinoconjunctivitis, and atopic eczema: ISAAC. The Lancet, 351, pp. 1225,1998 .

[2] Schäfer, T., Ring, J., Epidemiology of allergic diseases. Allergy, 52 (38), pp. 14-22, 1997.

[3] Wallace, L., Pellizzari, E., Hartwell, T.D., Perritt, R., Ziegenfuß, R., Exposure to benzene and other volatile compounds from active and passive smoking. Arch Environ Health, 42 (5), pp. 272-279, 1987.

[4] Wieslander, G., Norbäck, D., Björnsson, E., Janson, C., Boman, G., Asthma in the indoor environment: The significance of emission of formaldehyde and volatile organic compounds from new painted indoor surfaces. Int Arch Env Health, 69, pp. 115-124, 1997.

[5] Norbäck, D., Björnsson, E., Janson, C., Widström, J., Boman, G., Asthmatic symptoms and volatile compounds formaldehyde and $\mathrm{CO}_{2}$ Occ Env Med, 52, pp. 388-395, 1995.

[6] Tager, I.B., Hanrahan, J.P., Tosteson, T.D., Castile, R.G., Brown, R.W., Weiss, S.T., Speizer, F.E., Lung function pre- and postnatal smoke 
exposure and wheezing in the first year of life. Am Rev Respir Dis, 147, pp. 811-817, 1993.

[7] Etzel, R.A., Indoor air pollution and childhood asthma: effective environmental interventions. Environ Healt. Pers., 103 (6), pp. 55-58, 1995.

[8] Skolnick, E.T., Vonvolakis, M.A., Buck, A., Mannino, M.A., Sun, L.S., Exposure to Environmental Tobacco Smoke and the Risk of Adverse Respiratory Events in Children Receiving General Anesthesia. Anethesiology 88, pp. 1141-1142, 1998.

[9] Knight, J.M., Eliopoulos, C., Klein, J., Greenwald, M., Koren, G., Pharmacokinetic Predisposition to Nicotine from Environmental Tobacco Smoke: A Risk Factor for Pediatric Asthma. J Asthm, 35 (1), pp. 113-117, 1998.

[10] Wahn, U., Environmental factors facilitating allergic sensitization and atopic manifestation in early childhood. Nutrition Research, 18, pp. 13631371, 1998.

[11] Kulig, M., Luck, W., Lau, S., Niggemann, B., Bergmann, R., Klettke, U. et al., Effect of pre and postnatal tobacco smoke exposure on specific sensitization to food and inhalant allergens during the first 3 years of life. Multicenter Allergy Study Group, Germany. Allergy, 54 (3), pp. 220-228, 1999.

[12] Joad, J.P., Smoking and pediatric respiratory health. Clin Chest Med, 21(1), pp. 37-46, 2000.

[13] IARC Working Group: Tobacco smoking 38, pp. 1-421, 1985.

[14] Diez, U., Kroeßner, T., Rehwagen, M., Richter, M., Wetzig, H., Schulz, R., et al., Effects of indoor painting and smoking on airway symptoms in atopy risk children in the first year of life results of the LARS-study. Int $J$ Hyg Environ Health, 203, pp. 23-28, 2000.

[15] Hajimiragha, H., Ewers, U., Brockhaus, A., Boettger, A., Levels of benzene and other volatile aromatic compounds in the blood of nonsmokers and smokers. Int Arch Occup Environ Health, 61, pp. 513-518, 1989.

[16] Rolle-Kampczyk, U., Herbarth, O., Rehwagen, M., Noninvasive diagnostic methods in environmental medicine - Biomonitoring of specific exposure dependent Metabolites. J Env Med, 1, pp. 65-70, 1999.

[17] Ong, C.N., Lee, L.B., Determination of benzene and its metabolites application in biological monitoring of environmental and occupational exposure to benzene. J Chromatogr B, 660, pp. 1-22, 1994.

[18] Greim, H., Csanady, G., Filser, J.G., Schwarz, L., Wolff, Th., Werner, S., Biomarkers as Tools in Human Health Risk Assessment. Clin Chem, 12, pp. 1804-1808, 1995.

[19] Ikeda, M., Exposure to complex mixtures: implications for biological monitoring. Toxicol Lett, 77, pp. 85-91, 1995.

[20] Lowry, L.K., Role of biomarkers of exposure in the assessment of health risks. Toxicol Lett, 77, pp. 31-38, 1995. 
[21] Van Sittert, N.J., Booggaard, P.J., Beulink, G.D.J., Application of the urinary S-phenylmercapturic acid test as a biomarker for low levels of exposure to benzene in industry. Br J Ind Med, 50, pp. 460-469, 1993.

[22] Takahashi, S., Matsubara, K., Hasegawa, M., Akane, A., Shiono, H., Detection and measurement of S-benzyl-N-acetylcysteine in urine of toluene sniffers using capillary gaschromatography. Arch Toxicol, 67, pp. 647-650, 1993.

[23] Takahashi, S., Kagawa, M., Shiwaku, K., Matsubara, K., Determination of S-benzyl-N-acetyl-L-cysteine by Gas Chromatograhy/Mass Spectrometry as a new marker of toluene Exposure. J Anal Toxicol, 18, pp. 78-80, 1994.

[24] Angerer, J., Schildbach, M., Krämer, A., S-p-toluylmercapturic acid in the urine of workers exposed to toluene: a new biomarker for toluene exposure. Arch Toxicol, 72, pp. 119-123, 1998.

[25] Boogaard, P.J., van Sittert, N.J., Biological monitoring of exposure to benzene: a comparison between S-phenylmercapturic acid, trans, transmuconic acid, and phenol. Occup Environ Med, 52, pp. 611-620, 1995.

[26] Einig, D., Dunemann, L., Dehnen, W., Sensitive gas chromatographic method for determination of mercapturic acids in human urine. $J$ Chromatogr B, 687, pp. 379-385, 1996.

[27] Norström, A., Andersson, B., Aringer, L., Levin, J.O., Löf, A., Näslund, P., Wallen, M., Determination of specific mercapturic acids in human urine after experimental exposure to toluene or o-xylene. IARC SciPubl, 89, pp. 232-234, 1988.

[28] Rolle-Kampczyk, U., Rehwagen, M., Herbarth, O., Is the Internal Burden in Human Beings reflected by Air Pollution Measurements? Air Pollution, 7, pp. 447-455, 1999. 